\title{
SpineCore treatment for juvenile idiopathic scoliosis
}

\author{
Christine Coillard*, Alin B Circo, Charles-Hilaire Rivard \\ From 7th International Conference on Conservative Management of Spinal Deformities \\ Montreal, Canada. 20-22 May 2010
}

\section{Introduction}

The natural history of juvenile idiopathic scoliosis (patients who are least 4 years of age but younger than ten when the deformity is first identified) is usually a progression. In addition, patients who receive a diagnosis at five years or younger have a high chance of progression to a large curve, witch may lead to pulmonary and cardiac complications. The mainstay of conservative treatment for scoliosis (juvenile as well as for the adolescent) is the brace. The purpose of this prospective interventional study was to evaluate the effectiveness of the Dynamic SpineCor brace for juvenile idiopathic scoliosis and to evaluate the stability of the spine after the weaning point.

\section{Material and methods}

From 1993 to 2009, 150 juvenile patients were treated by the SpineCor brace. 67 patients had a definite outcome and 83 are still actively being treated. The assessment of brace effectiveness was done following the outcome criteria recommended by the SRS.

\section{Results}

Concerning the 67 patients with a definite outcome, $32.9 \%$ corrected their Cobb angle with at least $5^{\circ}$ and $10.5 \%$ had a stabilization of their Cobb angle. Out of all patients with a definite outcome, $37.3 \%$ of patients had surgical recommendation before skeletal maturity. Looking at the stability of the curves 2 years after the end of the treatment, $14.3 \%$ of the patients continued their correction even without the brace and $71.4 \%$ remained stable.

Sainte-Justine Hospital, Montreal, Canada

Full list of author information is available at the end of the article

\section{Discussion}

It seems that the effectiveness of the SpineCor brace in obtaining and maintaining the neuromuscular integration of the corrective movement can be achieved even for the juvenile patients since over $85 \%$ of all patients that finished the treatment remained stable and some even corrected their Cobb angle after the brace was discontinued.

\section{Conclusion}

In conclusion, the SpineCor brace is effective for the treatment of juvenile idiopathic scoliosis and it seems that the results are better with an early bracing. Moreover, the positive outcome appears to be maintained in the long term.

Published: 10 September 2010

doi:10.1186/1748-7161-5-S1-O52

Cite this article as: Coillard et al:: SpineCore treatment for juvenile idiopathic scoliosis. Scoliosis 2010 5(Suppl 1):052.

Submit your next manuscript to BioMed Central and take full advantage of:

- Convenient online submission

- Thorough peer review

- No space constraints or color figure charges

- Immediate publication on acceptance

- Inclusion in PubMed, CAS, Scopus and Google Scholar

- Research which is freely available for redistribution 